\title{
Increasing the Wear Resistance of Metallic Materials by applying Thermochemical Treatments
}

\author{
Florin $\mathrm{Ciofu}^{* 1}$ \\ ${ }^{1}$ Lucian Blaga University of Sibiu, Faculty of Engineering, Industrial Engineering and Management \\ Department, Romania
}

\begin{abstract}
Wear is defined as mechanical or physical damage to a contact surface by another as a result of a relative movement. The structure of the steels has a great influence on abrasion resistance, so that certain thermochemical treatments applied to steels, besides the structural changes, are also aimed at changes in the chemical composition in the superficial layers as a result of diffusion with certain elements. A highly used thermochemical treatment is the aluminization, especially as a process for increasing the wear resistance, of the hot oxidation resistance, in order to replace the expensive refractory alloys with heating resistance up to 800 $1000{ }^{\circ} \mathrm{C}$ with cheaper materials.
\end{abstract}

\section{Introduction}

By means of a thermo-chemical treatment, a part and other atoms besides carbon and nitrogen can be introduced into the surface of the surface to obtain specific properties such as anti-corrosive, refractory or wear-resistance properties.

Generally, the diffusing elements form solid iron substitution solutions. Aluminizing in solid medium is done in mixtures: $50 \%$ aluminum (powder), $49-49.5 \%$ aluminum oxide and $0.5-1 \%$ ammonium chloride. The samples are packed into the powder mixture in metal boxes and heated to $950-1050{ }^{\circ} \mathrm{C}$ where the reactions take place [1]:

$$
\begin{gathered}
\mathrm{NH}_{4} \leftrightarrow \mathrm{NH}_{3}+\mathrm{HCl} \\
6 \mathrm{HCl}+2 \mathrm{Al} \leftrightarrow 2 \mathrm{AlCl}_{3}+3 \mathrm{H}_{2} \\
\mathrm{AlCl}_{3}+\mathrm{Fe} \leftrightarrow \mathrm{FeCl}_{3}+\mathrm{Al}
\end{gathered}
$$

At $850{ }^{\circ} \mathrm{C}$ it is obtained a concentration of $18 \%$ in aluminum and $35 \%$ at $1000{ }^{\circ} \mathrm{C}$.

Cooling is done up to $400-500{ }^{\circ} \mathrm{C}$ in the oven and then into the air, followed by a homogenization annealing at $900{ }^{\circ} \mathrm{C}$ for $3 \mathrm{~h}$ in order to homogenize the layer.

The liquid aluminization is made in baths containing $92-94 \% \mathrm{Al}, 6-8 \% \mathrm{Fe}$ at $700-900 \mathrm{C}$.

After a 45-60 minute stay in the bath and a further annealing at $1100-1150{ }^{\circ} \mathrm{C}$ with a duration of $1.5-2$ hours a layer of $0.8-1.2 \mathrm{~mm}$ is obtained [1].

\footnotetext{
* Corresponding author: cristian.ciofu@ulbsibiu.ro
} 


\section{Materials and methods}

\subsection{Description of the experimental program}

Starting from the unfavorable influence of aluminum on the deforming ability and calorific ability of steels, a thermal treatment of aluminization of samples of $\mathrm{C} 45$, which had previously been deposited with laser-sintering technology, additional layers consisting of a $\mathrm{TiB}_{2}$ powder $(20 \%)$ mixed with $316 \mathrm{~L}(80 \%)$ steel. The powder mixture was deposited on the surface of a $4 \mathrm{~mm} \mathrm{C45}$ plate type piece.

The sintering was carried out at a temperature of about $2200{ }^{\circ} \mathrm{C}$. The power of the laser plant was set at $1.5 \mathrm{~W}$ with a $50 \%$ load factor. Sintering takes place in the presence of solid phase. Because the particles deposited in this experiment have the size of $2 \div 4 \mu \mathrm{m}$ (very small size), the densification is high, the resulting pores being relatively small and closed (fig. 1).

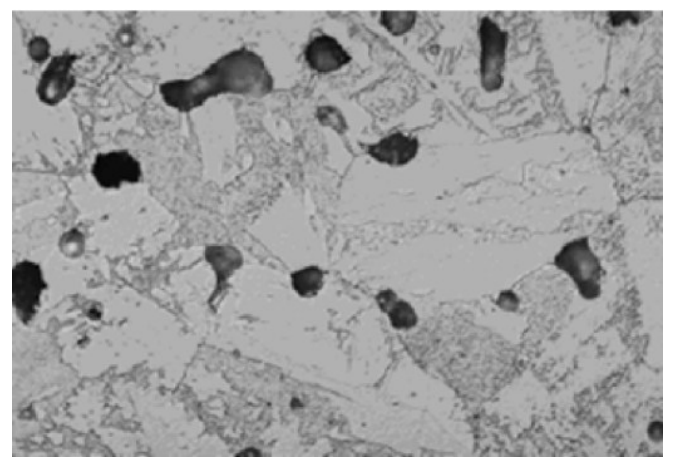

Fig. 1. Dense structure obtained by laser sinteringof the mixture of $20 \% \mathrm{TiB}_{2}$ and $80 \% 316 \mathrm{~L}$ on flat surface $\mathrm{C} 45 ; \mathrm{P}=1.5 \mathrm{~W} ; 50 \%$ load factor. (400x optical)

The superficial aluminum enrichment of the samples was carried out by maintaining different temperatures at $820{ }^{\circ} \mathrm{C}$ and $860{ }^{\circ} \mathrm{C}$ in a molten aluminum bath containing $90 \%$ aluminum ( $\mathrm{Al}$ 99.7) and 10\% iron powder introduced to protect the corrosion them.In order to avoid oxidation of the aluminum melt, a layer of the fondant having the composition shown in Table 1 was deposited at its surface [2].

Table 1. Composition of the fondant layer

\begin{tabular}{|c|c|c|c|c|}
\hline $\begin{array}{c}\text { Composition } \\
{[\%]}\end{array}$ & $\mathrm{NaCl}$ & $\mathrm{KCl}$ & $\mathrm{Na}_{3} \mathrm{AlF}_{6}$ & $\mathrm{AlF}_{3}$ \\
\cline { 2 - 5 } & 40 & 40 & 10 & 10 \\
\hline
\end{tabular}

A ceramic crucible was used to carry out the experiment, which was filled with $900 \mathrm{~g}$ of aluminum and $100 \mathrm{~g}$ of iron powder, so that after the melting of the charge, the filling rate of the crucible was $75 \%$.

Table 2. Aluminization regime

\begin{tabular}{|c|c|c|c|}
\hline \multirow{2}{*}{ Sample } & \multicolumn{3}{|c|}{ Aluminization regime } \\
\cline { 2 - 4 } & $\mathrm{T}\left[{ }^{\circ} \mathrm{C}\right]$ & Holding time [min] & $\begin{array}{c}\text { Cooling } \\
\text { medium }\end{array}$ \\
\hline 1 & 820 & 50 & oil \\
\hline 2 & 820 & 50 & oil \\
\hline 3 & 860 & 60 & oil \\
\hline 4 & 860 & 60 & oil \\
\hline
\end{tabular}


The crucible was introduced into the electric furnace and heated to $800{ }^{\circ} \mathrm{C}$, so that the aluminum melted, encompassing the iron powder. Immediately after the melting of the aluminum, the metal bath was covered with a layer of fondant with a thickness of about 10 $\mathrm{mm}$. Thereafter, the metal melt in the above-described form was further heated to temperatures of $820^{\circ} \mathrm{C}$ and $860^{\circ} \mathrm{C}$ respectively. At this point the samples were introduced in turn into the melting bath and maintained for a period of time according to a previously established schedule (Table 2) [2];

\subsection{Structure and properties of the aluminized layer}

The structure of the aluminized layer, namely the nature, the sequence and the morphology of the various structural constituents, are determined directly by the concentration and the distribution of the aluminum in the diffusion layer. The constituents in the alloyed layer correspond to the one-phase fields of the iron-aluminum balance diagram. The concentration and distribution of aluminum in the superficial layer is determined both by the alloying process used and the technological parameters chosen (temperature and duration of maintenance) and the type of aluminium steel.

Sample 1 - C 45 plate with the dimensions $\mathrm{h}=4 \mathrm{~mm}, \mathrm{~L}=80 \mathrm{~mm}, 1=50 \mathrm{~mm}$ on which a layer of powder mixture of $0.2 \mathrm{~mm}$ thickness was deposited. After applying the thermochemical aluminization treatment under the conditions described above, the microstructure shown in fig. 2 was obtained.

In the micro-structure of the sample we distinguish four successive areas, as follows:

1-outer layer mechanically adhered to the surface of the sample during bath extraction with a thickness of about $0.15 \mathrm{~mm}$ and an irregular interface as a result of inter-diffusion processes between the two layers;

2-between the superficial layer of aluminum + phase and the deposited layer, a thin border of about $0.02 \mathrm{~mm}$, strongly attacked by the reagent, is observed [2,3];

3-layer deposited from the powder mixture, weakly attacked, constitutes a mechanical mixture of aluminum with a powder blend of $0.2 \mathrm{~mm}$ thick;

4-base mass sample, which exhibits a fine absorptive structure, being extensively attacked by the reagent;

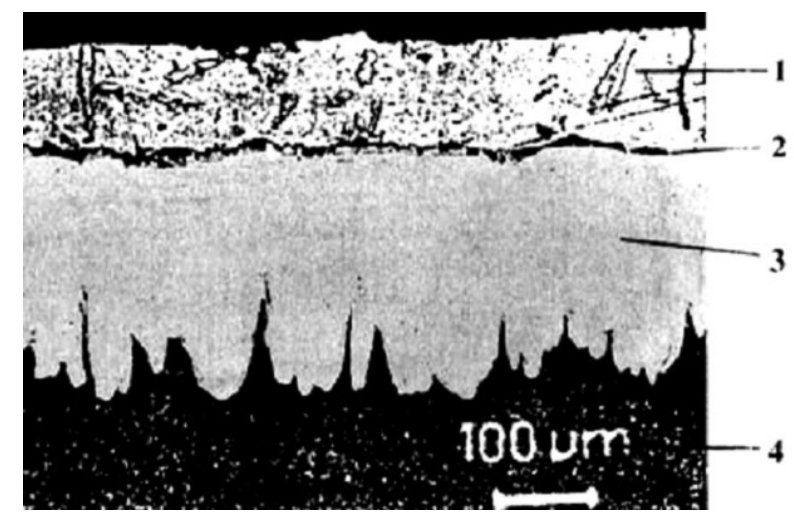

Fig. 2. Micro-structure of the sample 1

(the thickness of the deposited layer $\mathrm{h}=0.2 \mathrm{~mm}$, optically $100 \mathrm{x}$ ).

Sample 2 - Plate of C 45 with the dimensions $\mathrm{h}=4 \mathrm{~mm}, \mathrm{~L}=80 \mathrm{~mm}, 1=50 \mathrm{~mm}$ on which a powder mixture of $0.6 \mathrm{~mm}$ thickness was deposited. After the thermo-chemical treatment, resulted the micro-structure shown in fig. 3 . 
In the microstructure of the sample we distinguish four successive areas, as follows:

1 -outer layer mechanically adhered to the surface of the sample during bath extraction with a thickness of about $0.05 \mathrm{~mm}$. Lower thickness than sample 1 is due to the sampling rate of the sample in the crucible;

2-layer low-boundary border of about $0.01 \mathrm{~mm}$, consisting of phase $\theta[2,3]$;

3-layer deposited from the powder mixture, thicker than the sample 1 , of $0.6 \mathrm{~mm}$, presenting a sinuous contour to the piece;

4-base mass of the sample, which has a fine sorptive structure, being strongly attacked by the reagent [3];

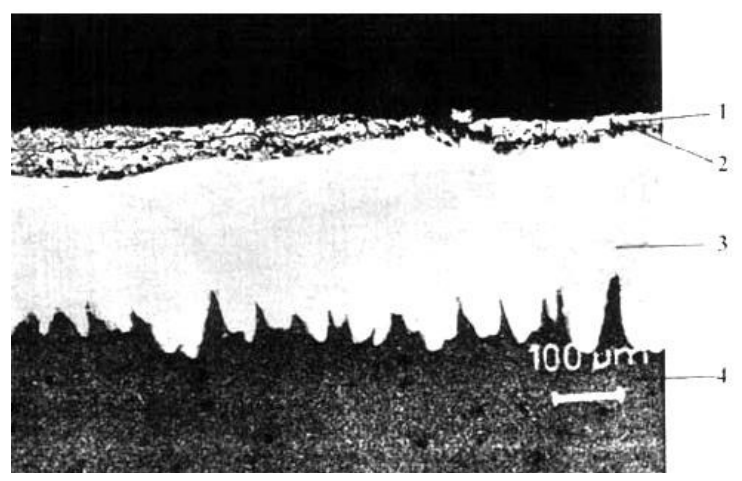

Fig. 3. Sample microstructure 2

(thickness of deposited layer $\mathrm{h}=0.6 \mathrm{~mm}$, optically $100 \mathrm{x}$ ).

Sample 3 - Plate of C 45 with the dimensions $\mathrm{h}=4 \mathrm{~mm}, \mathrm{~L}=80 \mathrm{~mm}, 1=50 \mathrm{~mm}$ on which a layer of powder mixture of $1 \mathrm{~mm}$ thickness was deposited. After thermochemical treatment, the microstructure shown in fig. 4 resulted.

In the microstructure of the sample we distinguish four successive areas, as follows:

1-layer outer layer mechanically adhered to the sample surface during bath extraction, with a thickness of about $0,1 \mathrm{~mm}$, made up of aluminum and phase $\theta$. An average thickness of $0,1 \mathrm{~mm}$ indicates a slow sample drawing rate in the crucible $[2,3]$;

2-layer low-boundary border of about $0,01 \mathrm{~mm}$, consisting of phase $\theta$;

3-layer coat of the $1 \mathrm{~mm}$ powder mixture also features a sinuous but sharper contour to the piece than the parts placed in the bath at $820^{\circ} \mathrm{C}$ [3];

4-he base mass of the sample, which has a fine sorptive structure, being strongly attacked by the reagent;

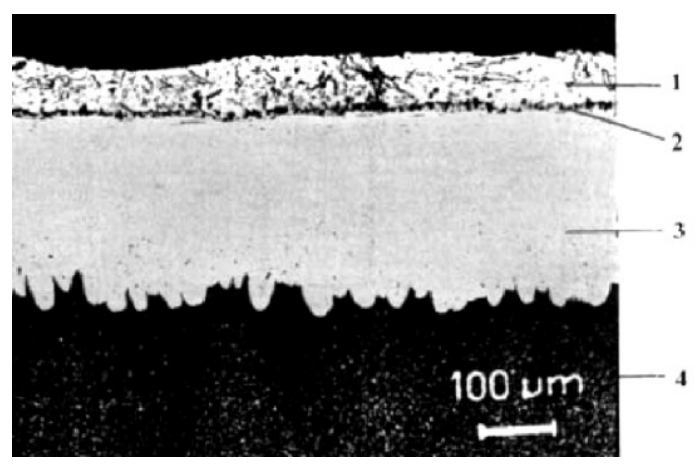

Fig. 4. Microstructure of sample 3

(thickness of deposited layer $\mathrm{h}=1 \mathrm{~mm}$, optically $100 \mathrm{x}$ ). 
Sample 4 - Plate of C 45 with the dimensions $\mathrm{h}=4 \mathrm{~mm}, \mathrm{~L}=80 \mathrm{~mm}, 1=50 \mathrm{~mm}$ on which a layer of powder mixture with a thickness of $1,2 \mathrm{~mm}$ was deposited. After the thermo-chemical treatment, resulted the micro-structure shown in fig. 4.

In the micro-structure of the sample we distinguish four successive areas, as follows:

1-outer layer mechanically adhered to the surface of the sample during bath extraction, with a thickness of about $0.12 \mathrm{~mm}$ made up of aluminum and phase $\theta$. An average thickness of $0.12 \mathrm{~mm}$ indicates a slow sample drawing rate in the crucible $[2,3]$;

2-boundary layer of low thickness of about $0.02 \mathrm{~mm}$, consisting of phase i;

3 -coat layer of the $1.2 \mathrm{~mm}$ powder mixture has a slightly sinuous contour towards the piece;

4-the base mass of the sample, which has a fine absorptive structure, being strongly attacked by the reagent $[4,5]$;

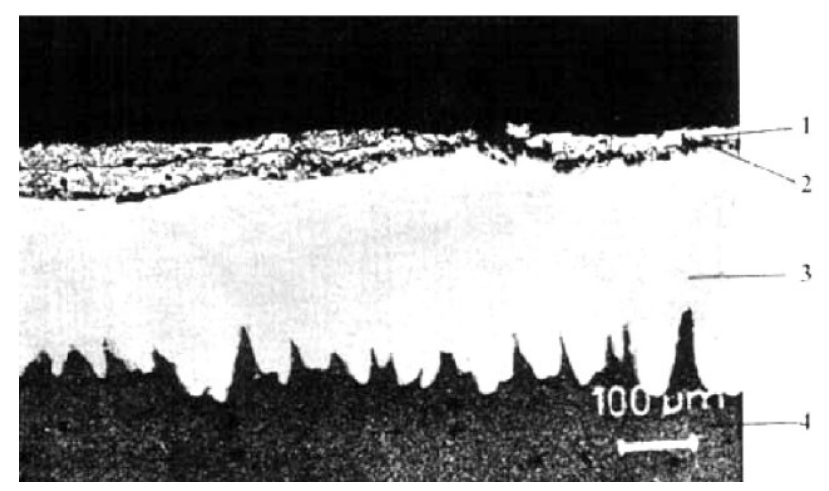

Fig. 5. Sample 4 micro-structure

(thickness of deposited layer $\mathrm{h}=1.2 \mathrm{~mm}$, optically $100 \mathrm{x}$ ).

\subsection{Determinations made on samples}

Working samples of the $4 \mathrm{~mm}$ thick $\mathrm{C} 45$ sheet pads on which the powder mixture was deposited were subjected to hardness measurements at different depths of the deposited coating as well as wear resistance measurements.

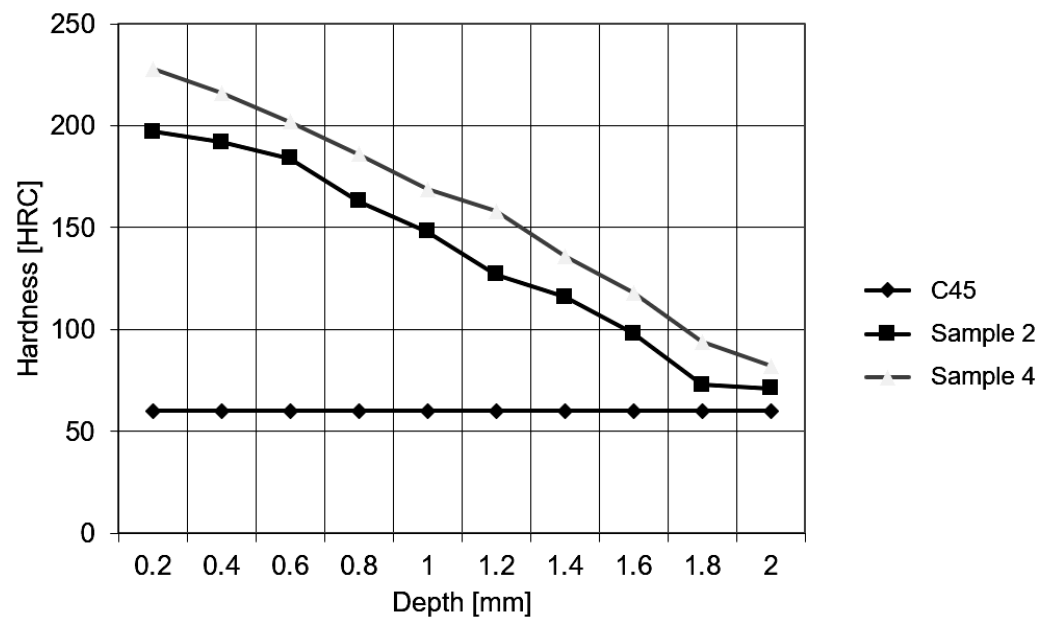

Fig. 6. Configuration of microhardness taken on the sample surface. 
The measurements to determine the micro-hardness were performed with a Reicherttype Vickers microhardness - testers at different depths of the deposited layer resulting in the distribution of values shown in Fig. 6. To be able to compare and see changes in hardness, measurements were also made on a piece made of $\mathrm{C} 45$ steel not subject to structural changes.

In order to determine the resistance to wear, a laboratory stand was used, having the following characteristics:

Contact type: plan, linear or punctual.

Sliding motion - sliding speeds ranging from 0,000001 to $0,018 \mathrm{~m} / \mathrm{s}$.

Contact pressures: $0.1 \mathrm{MPa} \ldots 5 \mathrm{Gpa}$.

Testing hard and soft materials and layers at low and very low speeds.

Friction modes: dry, boundary and mixed.

Use:

- Tribological passport experiments for any deposited material or layer;

- Determination of the thicknesses of deposited layers and the adhesion to the support material;

- Determination of the parameters of jerky movement (stick-slip phenomenon).

The values of the measurements made on the different samples according to the thickness of the powder coating layer deposited in order to determine the wear resistance are recorded in Tables 3-5.

Table 3. Values of the measurements made on samples with $0.6 \mathrm{~mm}$ thickness of powder mixture.

\begin{tabular}{|c|c|c|c|c|c|c|c|c|c|c|c|}
\hline \multirow{3}{*}{$\begin{array}{l}\text { Nr. } \\
\text { crt. }\end{array}$} & \multirow{3}{*}{$\begin{array}{c}\text { Percent } \\
\mathrm{TiB}_{2} \\
{[\%]}\end{array}$} & \multirow{3}{*}{$\begin{array}{c}\text { Force } \\
{[\mathrm{N}]}\end{array}$} & \multirow{3}{*}{$\begin{array}{c}\text { Initial } \\
\text { mass } \\
\mathrm{M}_{\mathrm{i}} \\
{[\mathrm{g}]}\end{array}$} & \multirow{3}{*}{$\begin{array}{c}\text { Final } \\
\text { mass } \\
\mathrm{M}_{\mathrm{f}} \\
{[\mathrm{g}]}\end{array}$} & \multirow{3}{*}{$\begin{array}{c}\text { Mass } \\
\text { variation } \\
\Delta \mathrm{M} \\
{[\mathrm{g}]}\end{array}$} & \multirow{3}{*}{$\begin{array}{c}\text { Sliding } \\
\text { speed } \\
\mathrm{V}_{\mathrm{a}} \\
{[\mathrm{m} / \mathrm{s}]}\end{array}$} & \multicolumn{5}{|c|}{ Time $[\mathrm{min}]$} \\
\hline & & & & & & & 0 & 15 & 30 & 45 & 60 \\
\hline & & & & & & & \multicolumn{5}{|c|}{$\Delta \mathrm{M}_{\mathrm{i}}[\mathrm{g}]$} \\
\hline 1 & \multirow{3}{*}{20} & 50 & \multirow{3}{*}{76.14} & 76.06 & 0.08 & 0.01 & 0 & 0.01 & 0.02 & 0.04 & 0.08 \\
\hline 2 & & 100 & & 76.03 & 0.11 & 0.01 & 0 & 0.03 & 0.04 & 0.09 & 0.11 \\
\hline 3 & & 150 & & 76.00 & 0.14 & 0.01 & 0 & 0.05 & 0.07 & 0.10 & 0.14 \\
\hline
\end{tabular}

Table 4. Values of the measurements made on samples with $1 \mathrm{~mm}$ thickness of powder mixture.

\begin{tabular}{|c|c|c|c|c|c|c|c|c|c|c|c|}
\hline \multirow{3}{*}{$\begin{array}{l}\mathrm{Nr} . \\
\text { crt. }\end{array}$} & \multirow{3}{*}{$\begin{array}{c}\text { Percent } \\
\mathrm{TiB}_{2} \\
{[\%]}\end{array}$} & \multirow{3}{*}{$\begin{array}{c}\text { Force } \\
{[\mathrm{N}]}\end{array}$} & \multirow{3}{*}{$\begin{array}{c}\text { Initial } \\
\text { mass } \\
\mathrm{M}_{\mathrm{i}} \\
{[\mathrm{g}]}\end{array}$} & \multirow{3}{*}{$\begin{array}{c}\text { Final } \\
\text { mass } \\
\mathrm{M}_{\mathrm{f}} \\
{[\mathrm{g}]}\end{array}$} & \multirow{3}{*}{$\begin{array}{c}\text { Mass } \\
\text { variation } \\
\Delta \mathrm{M} \\
{[\mathrm{g}]}\end{array}$} & \multirow{3}{*}{$\begin{array}{c}\text { Sliding } \\
\text { speed } \\
\mathrm{V}_{\mathrm{a}} \\
{[\mathrm{m} / \mathrm{s}]}\end{array}$} & \multicolumn{5}{|c|}{ Time [min] } \\
\hline & & & & & & & 0 & 15 & 30 & 45 & 60 \\
\hline & & & & & & & & & $\Delta \mathrm{M}_{\mathrm{i}}$ & & \\
\hline 1 & \multirow{3}{*}{15} & 50 & \multirow{3}{*}{74.86} & 74.74 & 0.15 & 0.01 & 0 & 0.04 & 0.07 & 0.11 & 0.15 \\
\hline 2 & & 100 & & 74.67 & 0.19 & 0.01 & 0 & 0.08 & 0.10 & 0.14 & 0.19 \\
\hline 3 & & 150 & & 74.60 & 0.26 & 0.01 & 0 & 0.10 & 0.13 & 0.16 & 0.26 \\
\hline
\end{tabular}

Table 5. Values of the measurements made on samples with $1.2 \mathrm{~mm}$ thickness of powder mixture.

\begin{tabular}{|c|c|c|c|c|c|c|c|c|c|c|c|}
\hline \multirow{3}{*}{$\begin{array}{l}\text { Nr. } \\
\text { crt. }\end{array}$} & \multirow{3}{*}{$\begin{array}{c}\text { Percent } \\
\mathrm{TiB}_{2} \\
{[\%]}\end{array}$} & \multirow{3}{*}{$\begin{array}{c}\text { Force } \\
{[\mathrm{N}]}\end{array}$} & \multirow{3}{*}{$\begin{array}{c}\text { Initial } \\
\text { mass } \\
\mathrm{M}_{\mathrm{i}} \\
{[\mathrm{g}]}\end{array}$} & \multirow{3}{*}{$\begin{array}{c}\text { Final } \\
\text { mass } \\
\mathrm{M}_{\mathrm{f}} \\
{[\mathrm{g}]} \\
\end{array}$} & \multirow{3}{*}{$\begin{array}{c}\text { Mass } \\
\text { variation } \\
\Delta \mathrm{M} \\
{[\mathrm{g}]}\end{array}$} & \multirow{3}{*}{$\begin{array}{c}\text { Sliding } \\
\text { speed } \\
\mathrm{V}_{\mathrm{a}} \\
{[\mathrm{m} / \mathrm{s}]}\end{array}$} & \multicolumn{5}{|c|}{ Time [min] } \\
\hline & & & & & & & 0 & 15 & 30 & 45 & 60 \\
\hline & & & & & & & & & $\Delta \mathrm{M}_{\mathrm{i}}$ & & \\
\hline 1 & \multirow{3}{*}{0} & 50 & \multirow{3}{*}{78.35} & 77.73 & 0.62 & 0.01 & 0 & 0.15 & 0.27 & 0.44 & 0.62 \\
\hline 2 & & 100 & & 77.57 & 0.78 & 0.01 & 0 & 0.23 & 0.38 & 0.52 & 0.78 \\
\hline 3 & & 150 & & 77.43 & 0.92 & 0.01 & 0 & 0.34 & 0.53 & 0.76 & 0.92 \\
\hline
\end{tabular}


The graphical interpretation of the centralized values in the table is shown in fig. 7, fig. 8 and fig. 9

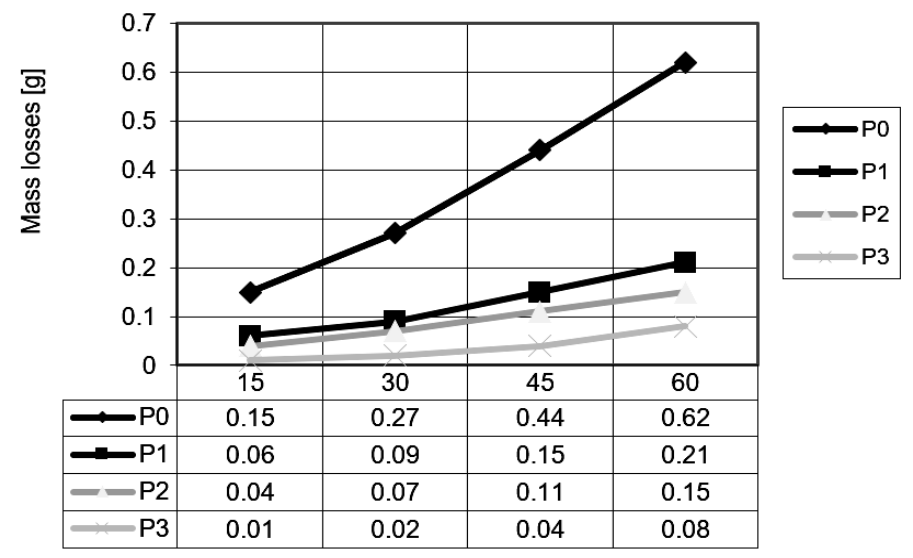

Time [min]

Fig. 7. Resistance to wear of samples at a pushing force of $50 \mathrm{~N}$; (P0 - C45; P1 - powder coat thickness $=0,6 \mathrm{~mm} ; \mathrm{P} 2$ - powder coat thickness $=1 \mathrm{~mm}$; P 3 - powder coat thickness $=1,2 \mathrm{~mm}$ )

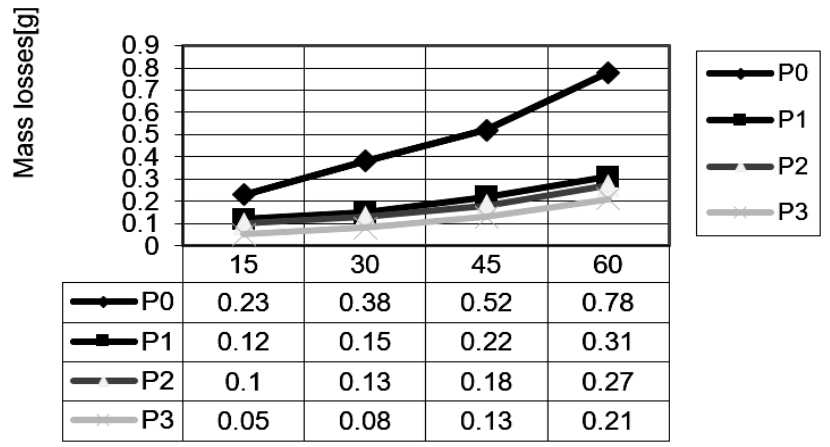

Time [min]

Fig. 8. Resistance to wearing of samples at a pushing force of $100 \mathrm{~N}$; (P0 - C45; P1 - powder coat thickness $=0,6 \mathrm{~mm} ; \mathrm{P} 2$ - powder coat thickness $=1 \mathrm{~mm} ; \mathrm{P} 3$ - powder coat thickness $=1,2 \mathrm{~mm}$ )

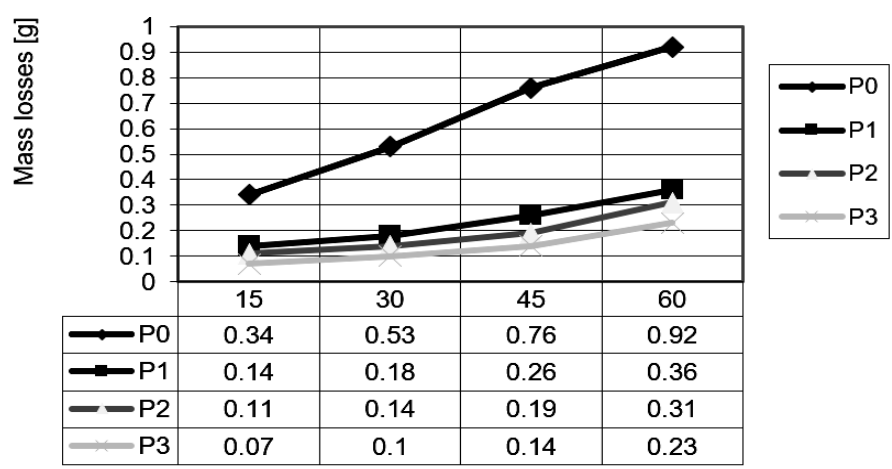

Time [min]

Fig. 9. Resistance to wear of samples at a pushing force of $150 \mathrm{~N}$; (P0 - C45; P1 - powder coat thickness $=0,6 \mathrm{~mm}$; P 2 - powder coat thickness $=1 \mathrm{~mm}$; P 3 - powder coat thickness $=1,2 \mathrm{~mm}$ ) 


\section{Conclusions}

From the examination of the microstructures presented in fig. 2, fig. 3 fig. 4 and fig. 5, the following conclusions are drawn:

- as expected, after the aluminization in the sample section resulted four successive zones, characteristic of the thermo-chemical treatment process used;

- the surface obtained a mechanically adhered layer during extraction from the aluminum bath. Its interface with the adjacent layer was, in all cases, irregular due to the inter-diffusion processes that occur during the aluminization between the metallic melt and the steel sample;

- the thickness of this first layer was variable from sample to sample depending on the rate of sample extraction from the melt bath;

- in the outer layer, the optical microscopic examination allowed to be emphasized that it is not only solidified aluminum but also phase $i$; between the superficial layer made of aluminum and the phase $\theta$ and the diffusion layer there is a presence of a thin boundary of $0,01-0,02 \mathrm{~mm}$, strongly attacked by the reagent;-the third layer is the aluminum diffusion area in the aluminum powder-rich powder mixture layer;

- the fourth layer (the base layer) did not undergo substantial structural changes [4-6];

In the case of the measurements made to determine the hardness it was found:- in the case of the deposition of $\mathrm{TiB}_{2}$ powder in the mixture with $316 \mathrm{~L}$ steel on $\mathrm{C} 45$ support there was an increase in material hardness which however decreased with the depth of the deposited layer, identifying with the base material (fig. 6);

In the case of the measurements made for the determination of wear resistance it was found:

- the wear resistance increased considerably with the increase in thickness of the deposited powder mixture layer (fig.7, fig. 8 and fig. 9) [7-8].

\section{References}

1. T. Dulamita, The technology of thermochemical treatments, E.D.P., 217 (1982)

2. F. Ciofu, Fiability and Durability, 1, 137 (2012)

3. F. Ciofu, WSEAS Conference, MEQAPS '13, Braşov, 310 (2013)

4. H.J.Brinkman, F. Zupanic, J. Duszczyk, L. Katgerman, Journal of Materials Research, 15/12, 2620-627 (2000)

5. D. Dobrotă, Metalurgija, 53, No.2 (2014)

6. D. Dobrotă, Journal of Adhesion Science and Technology, 27, Issue 2 (2003)

7. H.J., Brinkman, F. Zupanic, J. Duszczyk, L. Katgerman, Journal of Materials Research, 15/12, 2628-2635 (2000)

8. F. Ciofu, PhD Thesis, Sibiu (2007) 